\title{
Effects of maternal-fetal hyperoxygenation on aortic arch flow in a late-gestation human fetus with closed oval foramen at risk for coarctation
}

\author{
Thomas Kohl, MD, Giessen-Marburg, Germany
}

A 24-year-old pregnant woman was referred to our center at $36+0$ weeks of gestation. Fetal echocardiography revealed complete oval foramen closure, aortic isthmus hypoplasia (2.9 $\mathrm{mm}=\mathrm{Z}$-value -3.1$)$, and turbulent distal arch flow with an increased velocity of $175 \mathrm{~cm} / \mathrm{s}$.

On the basis of data by Matsui and colleagues ${ }^{1}$ that fetuses with isthmus Z-scores of 2 or less require surveillance or surgery for coarctation postnatally and that the prenatal detection of flow disturbance across the isthmus increases the odds ratio of true coarctation versus arch hypoplasia 16-fold, chronic intermittent maternal-fetal hyperoxygenation was offered to this patient. The experimental treatment approach was initiated at $36+1$ weeks of gestation after maternal informed consent, approval by the head of the local committee of human research, and in accordance with the ethical standards for human experimentation established by the Declaration of Helsinki.

Over 14 days, $45 \%$ of oxygen was administered to the mother via a face mask in 3 daily sessions of 3 to 4 hours' duration. This regimen has been found useful in previous cases to improve hypoplastic left heart dimensions by increasing pulmonary venous return to the left side of the heart in human fetuses. ${ }^{2}$ The effect of the approach on fetal left heart filling and aortic arch flow was assessed by multimodal fetal echocardiography (Figures 1 and 2). $\mathrm{Z}$-values of aortic isthmus dimensions before and at the end of treatment were derived from a Web site calculator (www.parameterz.com). ${ }^{3}$

After 14 days of maternal-fetal hyperoxygenation, the diameter of the aortic isthmus was measured at $4.1 \mathrm{~mm}$ (Z-value, -1.4). No maternal or fetal complications were observed. The fetus was delivered spontaneously at $38+1$ weeks of gestation. Neonatal echocardiography confirmed oval foramen closure and revealed the presence of an isthmus shelf with a flow increase to 200 $\mathrm{cm} / \mathrm{s}$. After closure of the ductus arteriosus at the second day of life, the infant could be discharged home without aortic arch intervention.

In conclusion, maternal-fetal hyperoxygenation in late gestation may be associated with increases in aortic arch dimensions. Such an effect should benefit fetuses at risk for coarctation.

\section{References}

1. Matsui H, Mellander M, Roughton M, Jicinska H, Gardiner HM. Morphological and physiological predictors of fetal aortic coarctation. Circulation. 2008;118: 1793-801.

2. Kohl T, Tchatcheva K, Stressig R, Geipel A, Heitzer S, Gembruch U. Maternal hyperoxygenation in late gestation promotes rapid increase of cardiac dimensions in fetuses with hypoplastic left hearts with intrinsically normal or slightly abnormal aortic and mitral valves. Ultraschall Med. 2008;29:92.

3. Pasquini L, Mellander M, Seale A, Matsui H, Roughton M, Ho SY, et al. Z-scores of the fetal aortic isthmus and duct: an aid to assessing arch hypoplasia. Ultrasound Obstet Gynecol. 2007;29:628-33.

\footnotetext{
From the German Center for Fetal Surgery \& Minimally Invasive Therapy, University Hospital of Giessen-Marburg, Giessen-Marburg, Germany.

Disclosures: Author has nothing to disclose with regard to commercial support.

Received for publication Sept 30, 2009; revisions received Nov 17, 2009; accepted for publication Nov 18, 2009; available ahead of print May 9, 2011.

Address for reprints: Thomas Kohl, MD, German Center for Fetal Surgery \& Minimally Invasive Therapy, University Hospital of Giessen-Marburg, Giessen-

Marburg, Germany (E-mail: thomas.kohl@uniklinikum-giessen.de).

J Thorac Cardiovasc Surg 2011;142:e67-9

$0022-5223 / \$ 36.00$

Copyright (C) 2011 by The American Association for Thoracic Surgery

doi:10.1016/j.jtcvs.2009.11.075
} 

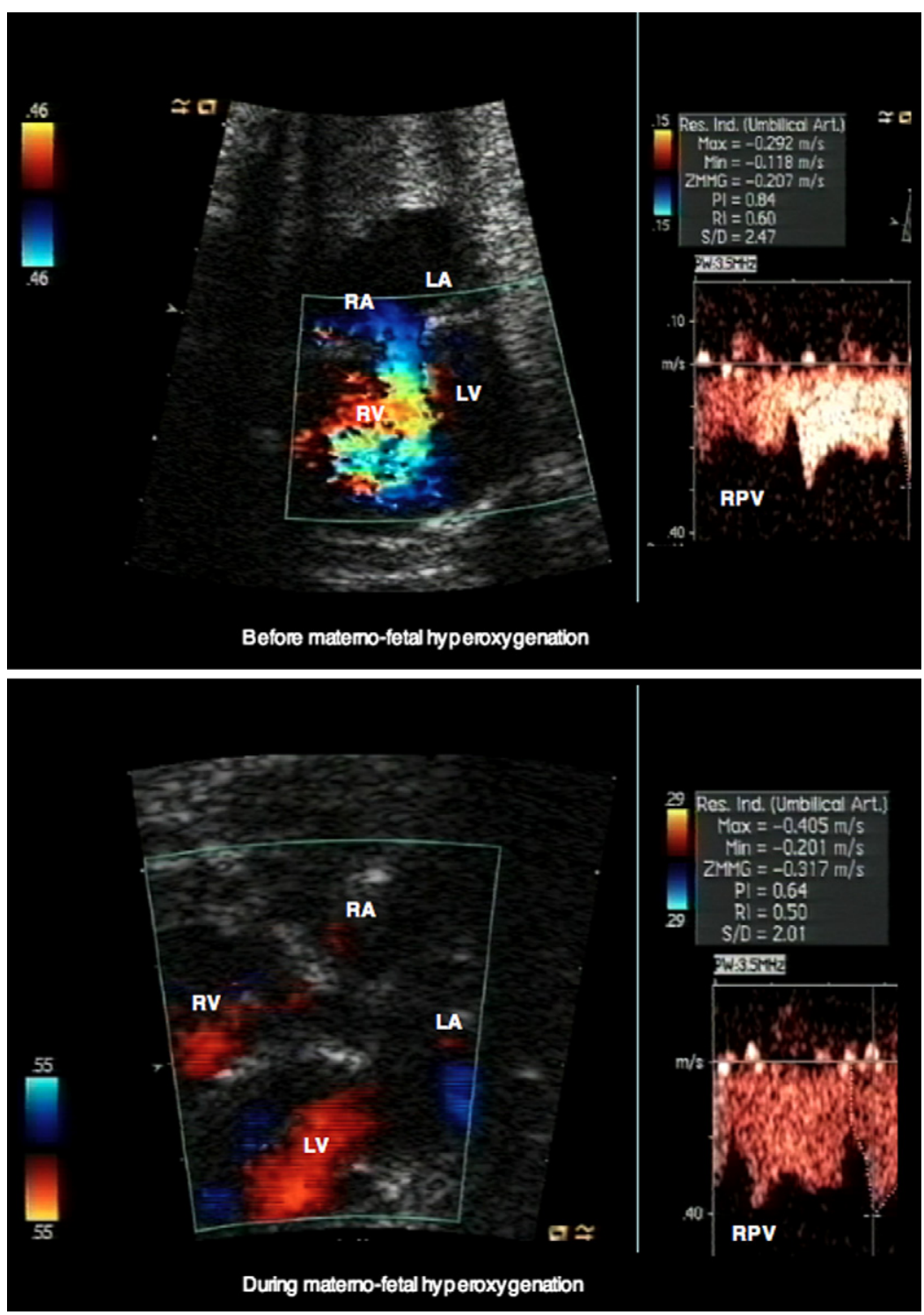

FIGURE 1. Effects of maternal-fetal hyperoxygenation on pulmonary blood flow and fetal left heart filling in this fetus with a closed oval foramen. Top left, Before hyperoxygenation, color Doppler imaging at a Nyquist limit of $46 \mathrm{~cm} / \mathrm{s}$ yields no discernable inflow into the left ventricle $(L V)$ but normal inflow into the right ventricle $(R V)$. Bottom left, In contrast, during hyperoxygenation, color Doppler imaging at an even higher Nyquist limit of $55 \mathrm{~cm} / \mathrm{s}$ and a less optimal interrogation angle yields a normal inflow signal into the LV. Top right and bottom right, The velocity time intregrals demonstrate Doppler flows in the central right pulmonary vein $(R P V)$ before (top) and during (bottom) maternal-fetal hyperoxygenation. Note the marked increase in pulmonary venous mean flow velocity. $R A$, Right atrium; $L A$, left atrium. 

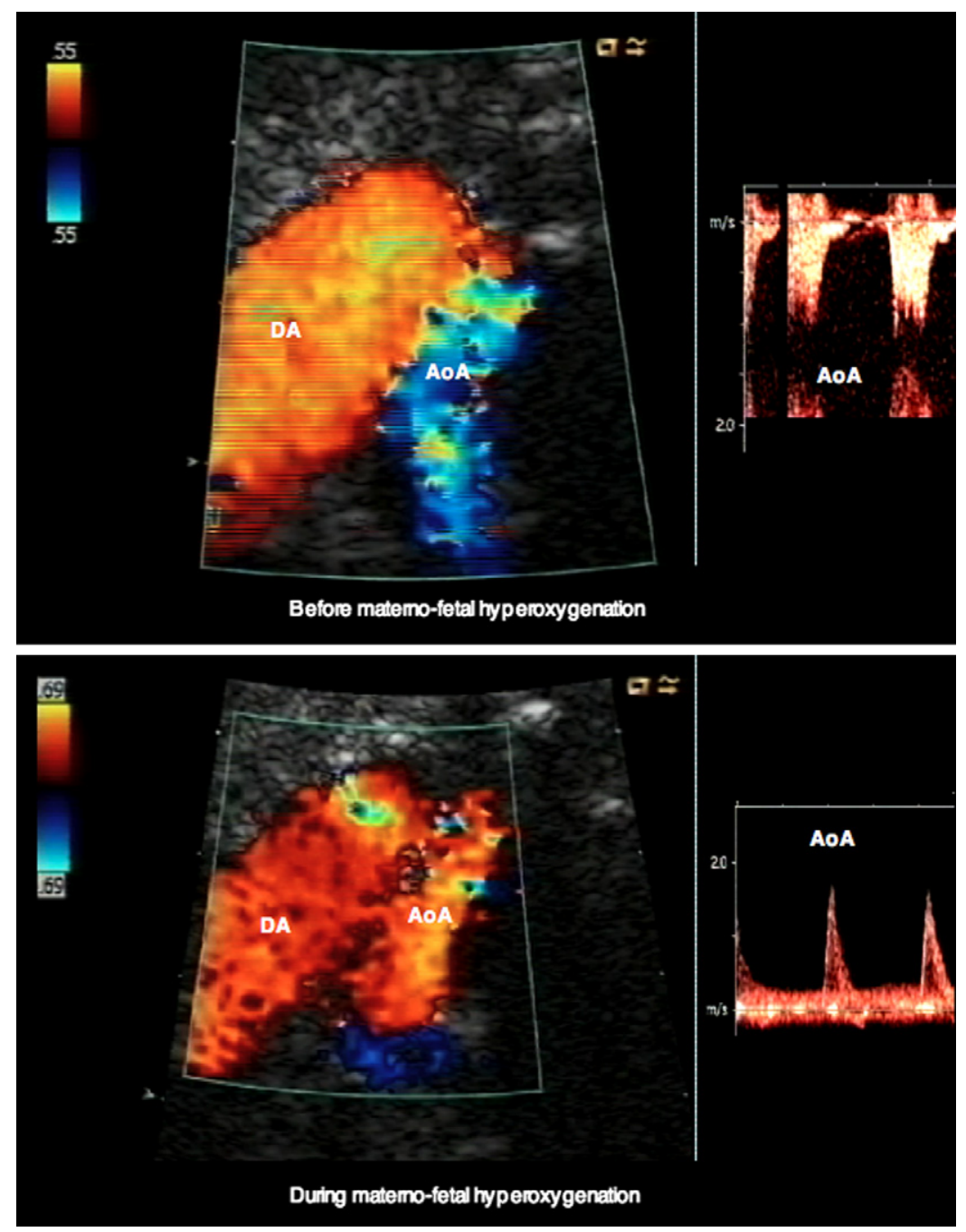

FIGURE 2. Improved left heart flow during maternal-fetal hyperoxygenation normalizes aortic arch flow direction in this fetus with a closed oval foramen. Images were taken on the last day of therapy. Top left and right, Before hyperoxygenation, color and pulsed Doppler imaging reveal abnormal retrograde blood flow within the aortic arch $(A o A)$. Bottom left and right, In contrast, during hyperoxygenation, color and pulsed Doppler imaging reveal normal antegrade flow within the aortic arch $(A o A)$. Over a treatment period of 14 days, these flow changes were accompanied with improvements in aortic isthmus Z-value. 